\title{
"REA: Educação para o Futuro": fomentando a inovação no design pedagógico
}

\author{
Rosiclei Aparecida Cavichioli Lauermann - UFSM - rcavich@gmail.com \\ Elena Maria Mallmann - UFSM - elena.ufsm@gmail.com \\ Camila Malu da Rosa - UFSM - camilamaludarosa@gmail.com \\ Fernando de Jesus Moreira Junior - UFSM - fmjunior777@ yahoo.com.br
}

\begin{abstract}
Resumo. A produção colaborativa de materiais é cada vez mais frequente na Web 2.0 e essa prática tem se estendido para o contexto educacional, o que implica na necessidade de inovações nas práticas escolares, as quais demandam a formação continuada dos professores. Nesse sentido, este artigo tem o propósito de apresentar e discutir os dados obtidos a partir de dois questionários online aplicados no início e no final da $1^{\circ}$ edição do Small Open Online Course (SOOC) "REA: Educação para o Futuro". As questões escolhidas para serem dialogadas neste artigo permitem verificar a compreensão dos docentes sobre o conceito Recursos Educacionais Abertos (REA) e realizar a análise das práticas pedagógicas dos participantes, antes e depois do curso. A análise de conteúdo foi o método utilizado para a análise das respostas às questões abertas, já as de avaliação com escala de 1 a 4 foram analisadas utilizando o Teste dos Sinais. Dessa forma, conclui-se que o curso sobre REA no formato SOOC potencializou a inovação didáticometodológica e curricular, a julgar pelas mudanças provocadas nas práticas escolares dos participantes como a preocupação com o tipo de licença do recurso disponível na internet e o desenvolvimento da Fluência Tecnológica-Pedagógica (FTP).
\end{abstract}

Palavras Chave: Recursos Educacionais Abertos. SOOC. Formação de professores. Educação aberta.

\section{"REA: Educação para o futuro": Fomenting innovation in pedagogical design}

Abstract. Collaborative production of materials is increasingly frequent in Web 2.0 and this practice has extended to the educational context, which implies the need for innovations in school practices. This demands the teachers' continuous training. Thus, this paper aims to present and discuss the data obtained from two online questionnaires applied at the beginning and end of the 1st edition of the SOOC course "REA: Education for Future". The questions chosen to be discussed in this paper allow us to verify teachers' understanding of OER concept and to analyze the participants' pedagogical practices before and after the course. Content analysis was the method used for these choices, as well as for the analysis of the answers to open questions. The evaluation questions with scale from 1 to 4 were analyzed using the Signal Test. Thus, we conclude that SOOC course about OER enhanced the didactic-methodological and curricular innovation, judging by changes provoked in participants' school practices, such as the preoccupation with the type of resource license available on internet and the development of Technological-Pedagogical Fluency (FTP).

Keywords: Open educational resources. SOOC. Teachers' continuous training. Open education.

\section{Introdução}

A produção colaborativa de materiais é cada vez mais frequente na Web 2.0 e propulsiona a autoria e coautoria. Essa prática tem se estendido também para o contexto educacional, o que impacta em mudanças na prática pedagógica em sala de aula e consequente necessidade de formação continuada dos professores. Nesse viés, os Recursos Educacionais Abertos (REA), com origem no movimento da Educação 
Aberta, apresentam-se como caminhos emergentes para coautoria na docência, haja vista o seu potencial de flexibilização à pluralidade cultural dos diferentes contextos educacionais creditados pelos 5R de abertura (WILEY, 2007, 2014) que são: reter, reusar, revisar, remixar e redistribuir.

Segundo Amiel e Soares (2016, p. 01) "ao longo da última década, o movimento de Recursos Educacionais Abertos conseguiu ganhar popularidade substancial", visto que sua produção vem sendo "superada por questões de aceitação, colaboração e sustentabilidade financeira". Essa superação se dá, pois "há quem defenda que a lógica da colaboração e do compartilhamento é a chave da sustentabilidade do futuro, dada a quantidade de bens tangíveis que deixam de ser tomados como posse para se tornarem acessíveis" (CIEB, 2016, sp).

Os REA têm despertado o interesse de professores, de pesquisadores, de instituições não governamentais de ensino e de órgãos públicos e o desenvolvimento de políticas públicas (BRASIL, 2014; UNESCO, 2011; UNESCO, 2015). Dessa forma, a Educação Aberta é uma "tentativa de buscar alternativas sustentáveis para algumas das barreiras evidentes no que tange ao direito de uma educação de qualidade" (AMIEL, 2012, p. 18).

$\mathrm{Na}$ procura de maneiras para concretizar as políticas de fomento à integração de REA nas práticas pedagógicas dos professores da rede pública do Rio Grande do Sul (RS), um Small Open Online Course (SOOC) sobre REA, denominado "REA: Educação para o Futuro" foi implementado pelo Grupo de Estudos e Pesquisas em Tecnologias Educacionais em Rede (GEPETER), do Centro de Educação de uma Universidade pública, com o objetivo de analisar em que medida o curso no formato SOOC sobre REA potencializa a autoria e coautoria de REA nas práticas escolares.

\section{MOOC, suas denominações e tendências emergentes}

De acordo com a UNESCO $(2015$, p. 1) os REA são "[...] materiais de suporte à educação que podem ser acessados, reutilizados, modificados e compartilhados livremente". Portanto, REA são cursos completos, partes de cursos, módulos, livros didáticos, artigos de pesquisa, vídeos, testes, software e qualquer outra ferramenta, material ou técnica (UNESCO, 2015). Nesse universo de possibilidades, os cursos MOOC, do acrônomo Massive Open Online Course, podem ser vistos como uma alternativa para promover e consolidar a educação aberta no contexto da cultura digital.

Dentre as características elencadas por McAuley et al. (2010) para definir cursos MOOC, destacamos serem cursos com recursos online compartilhados publicamente, de inscrição aberta e livre, podendo possuir um grande número de alunos, variando entre centena e milhares. Dessa forma possibilita o acesso ao conhecimento para um grande número de pessoas, que de outra forma poderiam ser excluídas por razões de localização geográficas, dificuldades financeiras e/ou tempo. Por isso, "um dos principais motivadores para o desenvolvimento de MOOC é o seu potencial para democratização do acesso ao conhecimento." (GARRIDO et al., 2018, p. 322).

A forma de implementação dos cursos MOOC deu origem a duas denominações: o xMOOC para classificar o modelo de ensino tradicional, estruturado na reprodução do conhecimento e o cMOOC fundamentado na produção de conhecimento num formato de ensino mais conectivista pautado no conhecimento construído com base na interação e colaboração, muitas vezes apoiada por redes sociais.

A partir de seus estudos, Mazzardo (2018, p. 74-75) elenca alterações no formato MOOC que podem ter provocado o surgimento de tendências emergentes: a) a busca por soluções para os problemas enfrentados como baixas taxas de conclusão; b) a necessidade de encontrar outras formas de avaliação e acreditação; c) a 
incompatibilidade do massivo com a excelência nos cursos online; d) a busca por novas fontes financeiras pelas universidades; e) avanço natural do MOCC; e f) a motivação financeira, pois existem tendências emergentes dos MOOC que permitem a cobrança pelas certificações. Os Small Private Online Courses (SPOC) e os Small Open Online Courses (SOOC) e outras designações similares são exemplos de tendências emergentes e derivações dos MOOC. Enquanto os SPOC são pequenos cursos online privados para uma quantidade reduzida de participantes, os SOOC são cursos online com inscrição aberta conforme critérios para delimitar um grande número de participantes, mas normalmente menor que um MOOC. Para Shimabukuro (2013), os SOOC possuem um número menor de participantes que nos MOOC e maior que nos cursos online tradicionais, o que possibilita o acompanhamento e feedback de um professor ou tutor.

\subsection{O curso SOOC "REA: Educação para o Futuro"}

O projeto intitulado "Formação de Professores da Educação Básica do RS: inovação didático-metodológica mediada por Recursos Educacionais Abertos (REA)"1 foi criado em 2017 com a meta de implementar programas de formação continuada de professores da educação básica no RS por meio de cursos no formato Small Open Online Course (SOOC) na plataforma livre Moodle.

Por consequência, a primeira edição do curso SOOC "REA: Educação para o Futuro" 2 , voltado aos professores e servidores da rede pública do ensino básico do estado do RS, ocorreu no segundo semestre de 2018, mais precisamente de agosto a novembro, a qual contou com o acompanhamento de uma equipe de professores e tutores. No primeiro semestre de 2019, entre abril e julho, ocorreu a segunda edição do curso e existe a previsão de mais uma edição para 2020.

O curso SOOC está organizado em quatro unidades: a) Recursos educacionais abertos com o objetivo de dar conhecimento ao conceito de REA, possibilitando a partir desse entendimento a identificação e seleção de REA nos repositórios de REA para a educação básica; b) Direitos autorais e licenças abertas com o propósito de debater sobre a Lei dos Direitos Autorais (Lei 9.610/98), licenças abertas como o Creative Commons, General Public License (GNU), Copyleft e Domínio Público; c) Material didático aberto - adaptação de REA - com a finalidade de desenvolver habilidades para identificar a abertura legal e técnica dos recursos e para adaptar/remixar os REA para a realidade educacional e d) Produção e compartilhamento de REA. Dessa forma o conteúdo programático do curso busca colocar em prática os 5R (WILEY, 2007, 2014) incentivando, assim, o desenvolvimento da Fluência Tecnológica-Pedagógica (FTP) (MALLMANN et al., 2013; PELZEL, 2019) dos participantes.

\section{Metodologia}

Os dados desta pesquisa são oriundos de um estudo exploratório realizado a partir de dois questionários online aplicado aos participantes da primeira edição do curso SOOC "REA: Educação para o Futuro". Segundo Marconi e Lakatos (2003, p. 188), o objetivo desse tipo de pesquisa "[...] é a formulação de questões ou de um problema, com tripla finalidade: desenvolver hipóteses, aumentar a familiaridade do pesquisador com um ambiente, fato ou fenômeno, para a realização de uma pesquisa futura mais precisa ou modificar e clarificar conceitos".

Segundo Oliveira (2016, p. 83), o uso do questionário como instrumento para produção de dados é uma técnica "para obtenção de informações sobre sentimentos, crenças, expectativas, situações vivenciadas e sobre todo e qualquer dado que o pesquisador(a) deseja registrar para atender os objetivos de seu estudo".

Os questionários foram disponibilizados no início e no final do curso. $\mathrm{O}$ 
Questionário Inicial (QI) objetivou diagnosticar o conhecimento prévio dos participantes sobre REA, informações sobre suas práticas docentes, bem como a infraestrutura de sua instituição de ensino, enquanto o Questionário Final (QF) teve a intenção de identificar as mudanças provocadas na prática docente a partir do curso e de avaliar a organização, os materiais e a implementação do curso.

O QI foi construído com 11 questões sendo 2 abertas, 3 de múltipla escolha e 6 de avaliação. Já o QF estava organizado em 28 perguntas sendo 3 abertas, 3 de múltipla escolha e 22 de avaliação. Segundo Marconi e Lakatos (2003, p. 206), as questões de múltipla escolha "são perguntas fechadas, mas que apresentam uma série de possíveis respostas, abrangendo várias facetas do mesmo assunto". Enquanto as questões de avaliação "consistem em emitir um julgamento através de uma escala com vários graus de intensidade para um mesmo item". Já as questões abertas "são as que permitem ao informante responder livremente, usando linguagem própria, e emitir opiniões. Possibilita investigações mais profundas e precisas", porém "a análise é difícil, complexa, cansativa e demorada" (MARCONI; LAKATOS, 2003, p. 204 e 206).

Ambos os questionários foram aplicados aos participantes da $1^{\text {a }}$ edição do curso, sendo que 48 participantes responderam os dois. As questões escolhidas para serem dialogadas neste texto permitem verificar a compreensão dos docentes sobre o conceito REA e realizar a análise das práticas pedagógicas dos mesmos antes e depois do curso.

A análise de conteúdo de Bardin (2011) foi o método utilizado para a análise das respostas às questões abertas. Nas questões de avaliação com escala de 1 a 4 foi aplicado o teste de normalidade Shapiro-Wilk, proposto por Shapiro e Wilk (1965) com a hipótese nula de que os dados provêm de uma população normal. Os $p$-valor obtidos foram muito próximos de zero, assim rejeitou-se a hipótese nula de normalidade com $5 \%$ de significância.

Como os dados não seguem uma distribuição normal, um teste não paramétrico, recomendado por Campbell, Lo e Mackinlay (1997) como alternativa aos testes paramétricos, é o Teste dos Sinais para amostras pareadas.

A regra de decisão no Teste dos Sinais consiste em rejeitar H0 quando o $p$-valor for inferior ao nível de significância de 5\%. As análises foram realizadas no software de análise estatística $\mathrm{R}^{3}$, para verificar se houve diferença nas respostas entre o QI e o QF. As hipóteses do teste são:

$\left\{\begin{array}{l}H 0: \text { Não existe diferença entre as respostas } \\ \text { H1: Existe diferença entre as respostas }\end{array}\right.$

\section{Discussão dos Dados e Resultados}

Consideramos como base para a análise das respostas das questões o número de 48 participantes que colaboraram nos QI e QF.

Antes de iniciar o curso, buscamos saber através da pergunta aberta "O que você sabe sobre Recursos Educacionais Abertos (REA)?" qual o entendimento que os participantes do curso possuíam sobre REA. A partir da análise de conteúdo realizada nos dados obtivemos o resultado representado na Figura 1. Neste momento é necessário informar que as respostas que apresentavam uma citação direta do conceito de REA foram desconsideradas, por entendermos que não fica claro o conhecimento do participante sobre o tema questionado. 


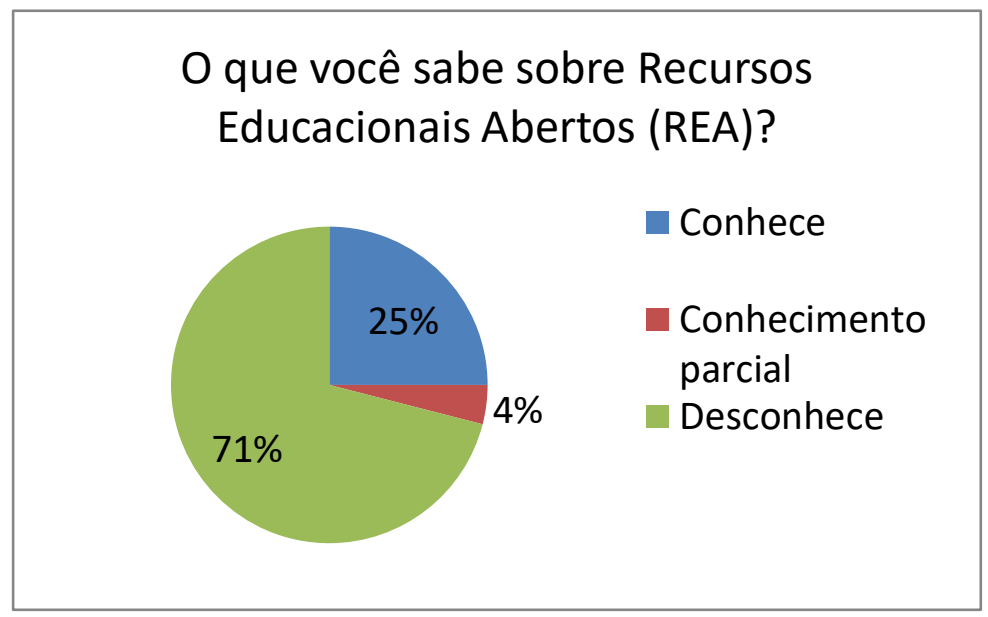

Figura 1 - Representação do conhecimento sobre REA

Fonte - os autores com base nos dados do QI

Observando a Figura 1, ficou evidente que grande parte dos professores da rede pública de educação básica no RS (71\%) desconhece os REA, embora estejam presentes em políticas públicas educacionais como o Plano Nacional de Educação (PNE). Mesmo para os $25 \%$ que indicaram conhecer REA, foi possível verificar, ao longo das atividades do curso, que havia lacunas para compreender como integrá-lo na prática pedagógica.

Com a intenção de investigar a frequência com que os recursos educacionais eram integrados nas práticas escolares dos participantes antes e depois do curso, realizamos uma comparação entre as questões de avaliação "Você costuma introduzir recursos educacionais digitais nas suas práticas escolares em sala de aula?" do QI e "Com que frequência você costuma integrar Recursos Educacionais Abertos (REA) nas suas atividades profissionais?" do QF.

Através do Teste dos Sinais obtivemos um $p$-valor $=0,0266$. Com isso, rejeitamos a hipótese nula com 5\% de significância, ou seja, existe uma diferença significativa entre as respostas em relação à frequência com que os REA passaram a ser introduzidos nas práticas profissionais. Esse resultado é corroborado através da Figura 2 que apresenta a comparação da frequência relativa das respostas dos participantes antes de iniciar o curso e ao final desse.

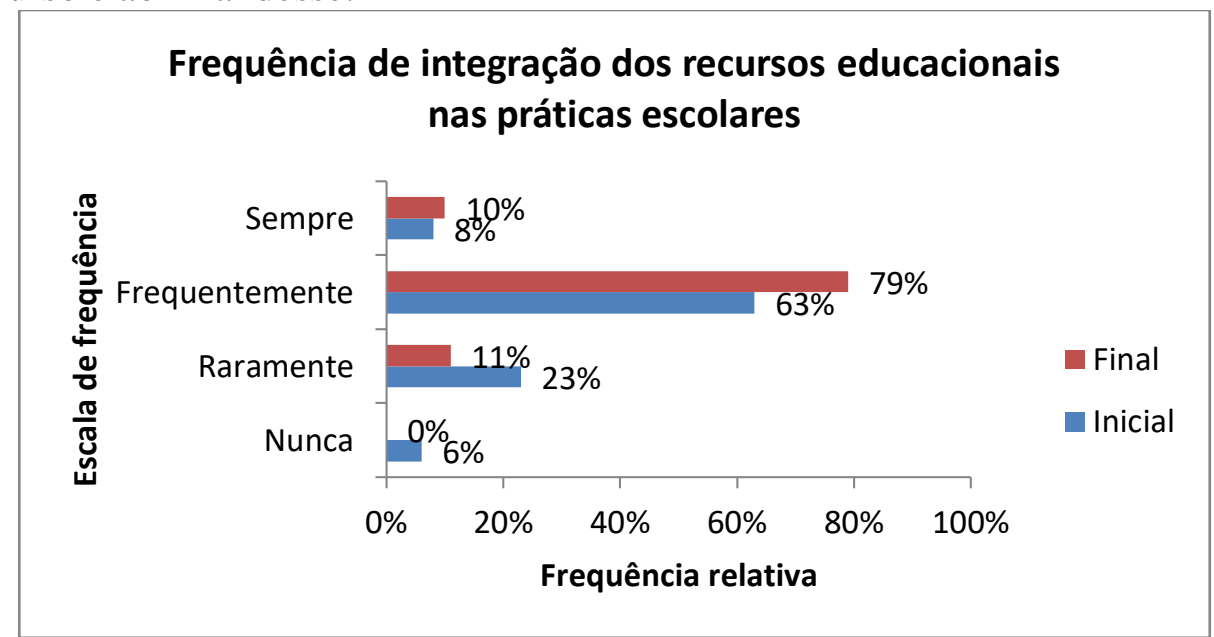

Figura 2 - Comparação da frequência de integração dos recursos educacionais nas práticas escolares

Fonte - os autores com base dos dados do QI e QF

Optamos por não usar a termo REA na questão do QI para evitar que professores V. $17 \mathrm{~N}^{\circ}$ 3, dezembro, 2019 RENOTE DOI: 
que não conhecessem esse conceito deixassem de responder de acordo com sua prática. Essa hipótese foi confirmada a partir dos dados obtidos e representados pela Figura 1. Observando a Figura 2, podemos constatar que o número de participantes que responderam frequentemente ou sempre integrar REA em suas práticas escolares aumentou, enquanto os que responderam raramente ou nunca, diminuiu. Sendo que nenhum participante respondeu no QF não integrar REA.

Com o propósito de analisar se os participantes mudaram seu comportamento em relação à preocupação com o tipo de licença dos materiais educacionais disponíveis na internet, comparamos as questões de avaliação "Você procura saber se o autor do recurso educacional escolhido concorda com o reuso, ou readaptação do material?" do QI e "Com que frequência você se preocupa em saber o tipo de licença de uso do recurso educacional pesquisado na internet?" do QF. Com um p-valor $=0,0033$, rejeitamos a hipótese nula com 5\% de significância, ou seja, existe uma diferença significativa entre as respostas em relação à preocupação com o tipo de licença dos recursos encontrados na internet.

Esse resultado também pode ser verificado na Figura 3, na qual podemos constatar que os participantes, após realizarem as atividades do curso SOOC, passaram a observar o grau de abertura dos recursos, produzindo reflexões sobre o fato de que nem tudo o que está na Internet está sob forma permissiva para o reuso, adaptação e redistribuição.

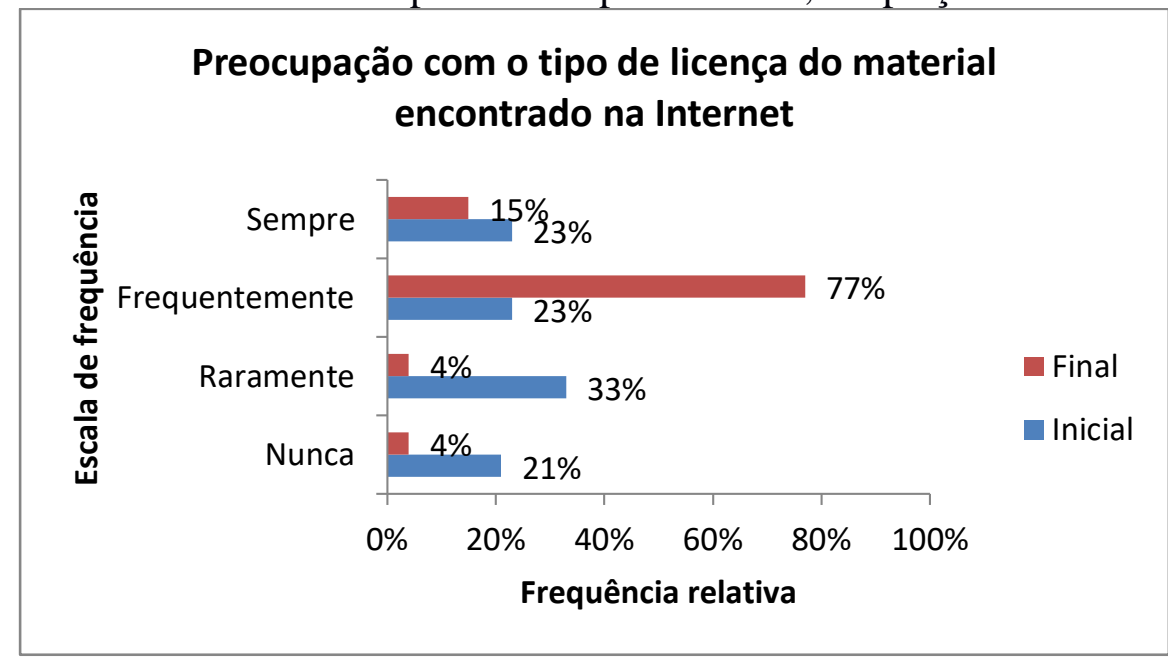

Figura 3 - Comparação da relação de observação do grau de abertura dos recursos pesquisados na Internet

Fonte - os autores com base nos dados do QI e QF

Ao analisar as respostas à pergunta de múltipla escolha "O curso "REA: Educação para o futuro" motivou-o a:", cujas opções de escolha eram: a) produzir REA; b) adaptar REA; c) distribuir REA e d) não se aplica, obtivemos o resultado exibido na Figura 4, no qual observamos que a grande maioria $(87,50 \%)$ sentiu-se motivada a produzir REA a partir da realização do curso SOOC, $75 \%$ sentiram incentivados a adaptar REA, enquanto apenas $47,92 \%$ sentiram encorajados a distribuir REA. Esse resultado converge com as dificuldades demonstradas pelos participantes durante a realização das atividades propostas durante o curso. Isso evidencia, mais uma vez, a dificuldade cultural dos professores tornarem-se autores dos próprios materiais didáticos. Essa prática é pouco valorizada pelas políticas públicas de formação e atuação docente haja vista o grande número de materiais didáticos comerciais que circulam nas escolas da rede pública. 


\section{O curso "REA: Educação para o futuro" motivou-o a:}

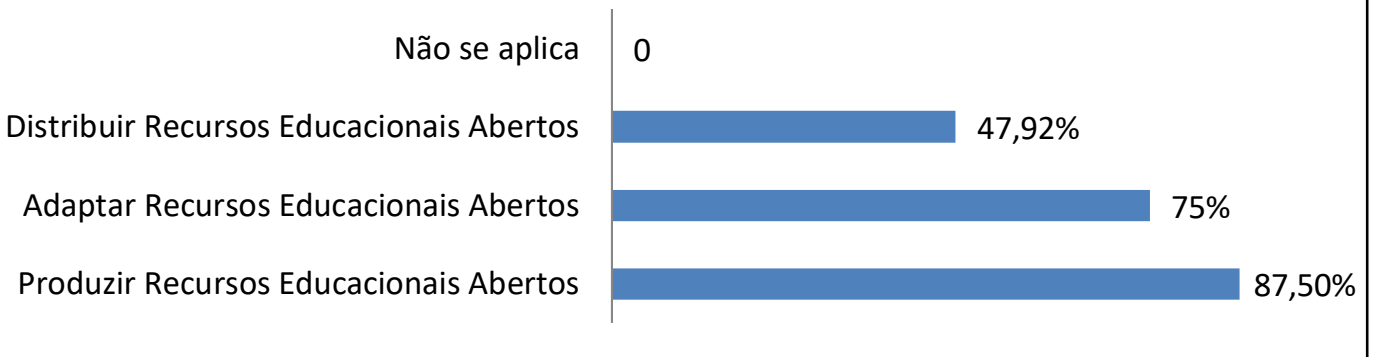

Figura 4 - Contribuições do curso

Fonte - os autores com base nos dados do QF

Nessa esteira de análise, buscamos investigar o quanto o curso SOOC implicou em mudanças no fazer pedagógico dos envolvidos através da questão de múltipla escolha "Que práticas profissionais você mudou a partir da realização do curso?". Analisando a Figura 5, podemos constatar que a maior mudança ocorreu na atenção aos diferentes tipos de licenças nos recursos (79\%), seguida da utilização de repositórios online para pesquisas REA (56\%). Esses resultados já seriam satisfatórios para considerarmos o alcance do curso. $\mathrm{O}$ fato de nenhum participante ter escolhido a opção "Não mudei minha prática profissional" certifica que conseguimos atingir o objetivo principal do curso que é fomentar mudanças nas práticas escolares e contribuir para $o$ desenvolvimento da FTP.

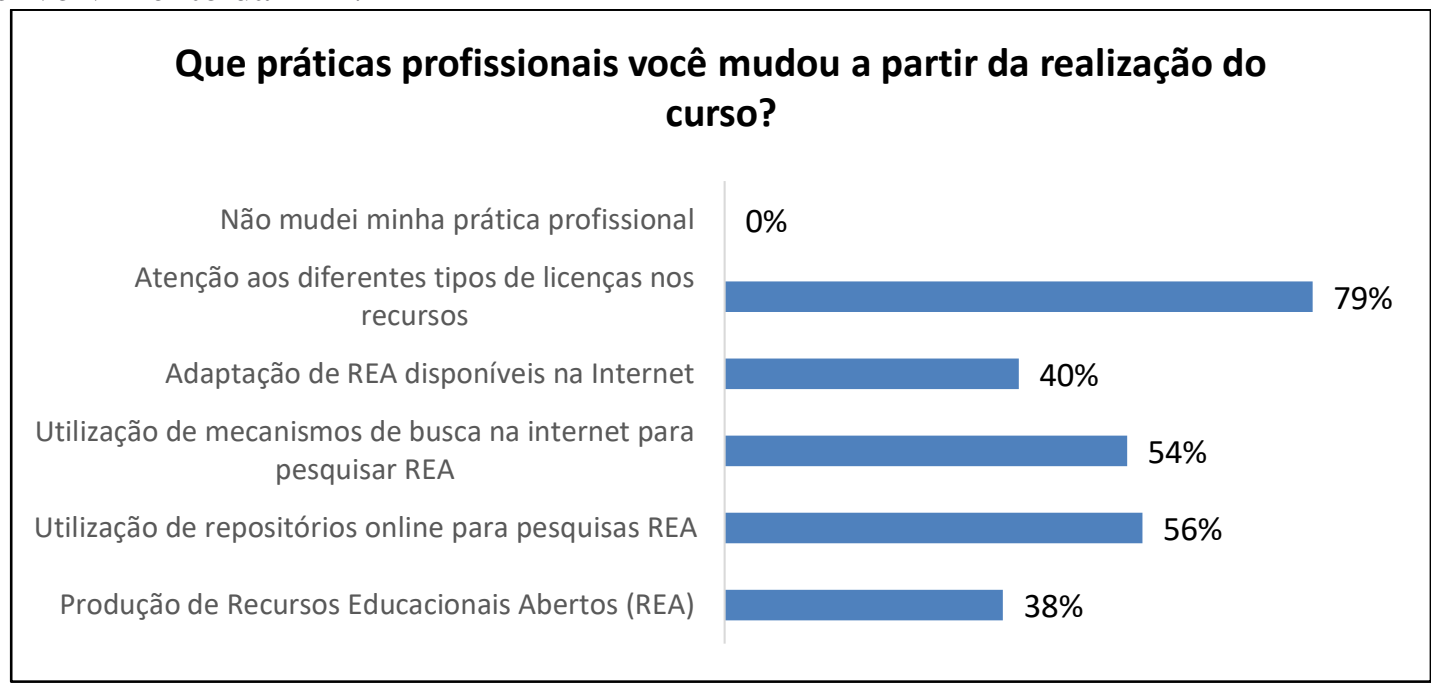

Figura 5 - Avaliação dos participantes ao final do curso em relação às práticas Fonte - os autores com base nos dados do QF

No aspecto que implica compartilhamento de REA, ao comparar as questões de avaliação que investigavam a cultura dos professores em compartilhar os REA utilizados nas práticas escolares com seus colegas obteve-se um $p$-valor $=0,86$. Com isso, a hipótese nula não foi rejeitada. Dessa forma, podemos inferir que não houve diferença na prática de compartilhamento de REA entre os professores, ou seja, quem já praticava o compartilhamento continuou praticando e quem não praticava, continuou sem praticar.

Esse resultado é confirmado quando realizamos a análise dos dados pela frequência relativa das respostas fornecidas pelos participantes antes e depois do curso, conforme podemos constatar na Figura 6. Isso vem ao encontro do resultado obtido na análise dos dados representando na Figura 4, ou seja, a ação de distribuir/compartilhar ainda não é 
uma prática comum entre os professores. Trata-se de mais um indicador que fundamenta a importância de ações de formação como essa em tela, visto que a valorização dos profissionais da educação básica também perpassa pela credibilidade e legitimidade dos recursos elaborados por eles mesmos, compartilhados e validados entre pares.

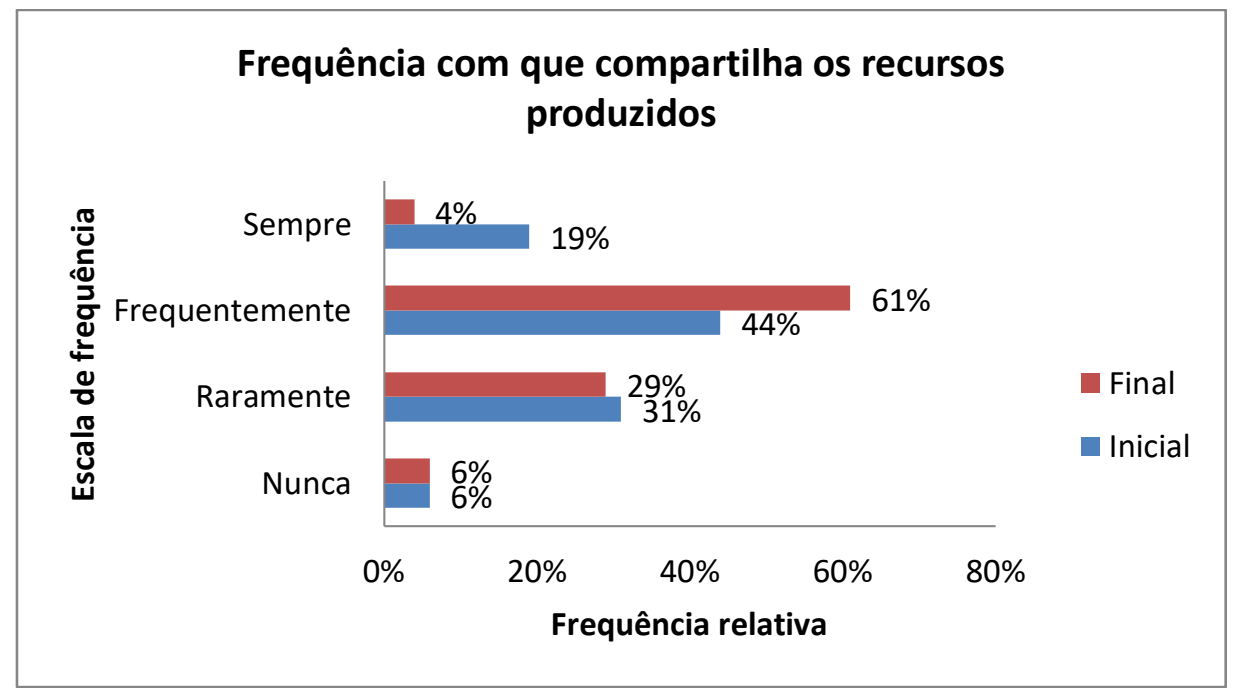

Figura 6 - Comparação da prática de compartilhar os recursos produzidos Fonte - os autores com base nos dados do QF

Para finalizar o recorte realizado na análise dos dados para este trabalho, apresentamos os resultados obtidos a partir da questão de avaliação "A implementação de cursos de formação continuada para professores no formato Small Open Online Courses (SOOC), totalmente a distância, potencializa a inovação didático-metodológica e curricular?". A representação da Figura 7 nos permite concluir que a realização do curso foi exitosa, correspondendo às expectativas da equipe organizadora e dos participantes ao potencializar a inovação didático-metodológica e curricular desde os movimentos de formação dos professores.

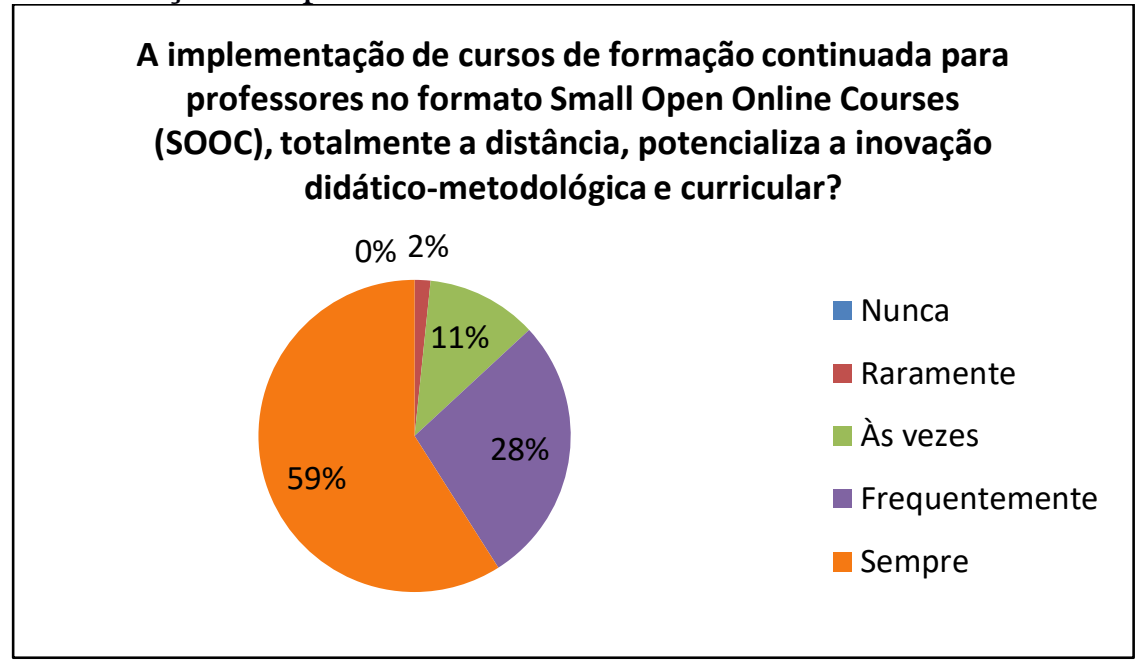

Figura 7 - Avaliação geral do curso pelos participantes

Fonte - os autores com base nos dados do QF

\section{Conclusão}

Os resultados, discutidos na seção anterior, mostram que o SOOC sobre REA para formação de professores foi uma importante ação educacional para produzir mudanças na prática docente ao considerar a compreensão, por parte dos participantes, da V. $17 \mathrm{~N}^{\circ}$ 3, dezembro, 2019 RENOTE DOI: 
definição de REA, bem como dos princípios basilares do REA, compreendidos como os 5R (WILEY, 2007, 2014). O que encorajou os participantes a utilizar recursos abertos na elaboração de seus planejamentos.

Ao propor atividades que contemplassem a efetivação dos $5 \mathrm{R}$ de abertura do REA, os participantes tornaram-se autores e coautores de REA, publicando-os na internet para que mais pessoas possam reutilizar. Isso está em acordo com as diretrizes e metas da legislação educacional vigente, como o Plano Nacional de Educação (PNE). Do mesmo modo, tem como propósito fomentar práticas inovadoras para melhoria das condições de permanência e conclusão dos estudos com sucesso já que os índices de reprovação e evasão continuam sendo preocupantes em todo estado.

Concluímos, portanto, que o curso no formato SOOC sobre REA potencializou a inovação didático-metodológica e curricular, a julgar pelas mudanças provocadas nas práticas escolares dos envolvidos. Além disso, contribuiu com o desenvolvimento da FTP (MALLMANN et al., 2013; PELZEL, 2019) necessária para colocar em prática os $5 \mathrm{R}$ e, assim, possibilitar a flexibilização à pluralidade cultural dos diferentes contextos educacionais. Por fim, o curso favoreceu a compreensão da cultura aberta na medida em que fomentou a autonomia e a autoria e coautoria de REA na docência efetivando, dessa forma, as políticas institucionais/internacionais sobre REA e da educação aberta em rede.

\section{Notas}

1 Pesquisa realizada com o financiamento do Conselho Nacional de Desenvolvimento Científico e Tecnológico (CNPq) e da Comissão de Aperfeiçoamento de Pessoal do Nível Superior (CAPES), viabilizada com o auxílio financeiro do Edital Pesquisador Gaúcho da Fundação de Amparo à Pesquisa do Estado do RS (FAPERGS).

2 O curso está disponível como REA no repositório do GEPETER no endereço http://gepeter.proj.ufsm.br/repositorio/items/show/5

${ }^{3} \mathrm{R}$ é um ambiente de software livre para computação e gráficos estatísticos (https://www.r-project.org/).

\section{Referências Bibliográficas}

AMIEL, T. Educação Aberta: configurando ambientes, práticas e recursos educacionais. In: SANTANA, B; ROSSINI, C.; PRETTO, N. de L. (org.). Recursos Educacionais Abertos: práticas colaborativas e políticas públicas. 1. ed. São Paulo: Casa da Cultura; Salvador: ADUFBA, 2012. p. 17-33.

AMIEL, T.; SOARES, T. C. Identifying Tensions in the Use of Open Licenses in OER Repositories. The International Review of Research in Open and Distributed Learning, v. 17, n. 3, 2016. Disponível em: http://www.irrodl.org/index.php/irrodl/article/view/2426. Acesso em: 15 jan. 2017.

BARDIN, L. Análise de conteúdo. Tradução Luís Antero Reto e Augusto Pinheiro. São Paulo: Edições 70, 2011.

BRASIL. Lei 13.005 de 25.06.14. Aprova o Plano Nacional de Educação - PNE e dá outras providências. Brasília, 2014. Disponível em: https://goo.gl/Ilj7cq. Acesso em: 28 set. 2017.

CAMPBELL, J. Y.; LO, A. W.; MACKINLAY, A. C. The econometrics of financial markets. 2th ed. New Jersey: Princeton University Press, 1997.

CIEB. Inovação aberta em educação: Conceitos e modelos de negócios. 2016. Disponível em: https://tinyurl.com/tpaqjjm. Acesso em: 12 mar. 2018. DOI: 
GARRIDO, F. A.; RÊGO, B. B. de; MATOS, E. de S. Modelando a interação (Humano-Computador) de um fórum de discussão para MOOC: MoLIC em uso. RENOTE, v. 16, n. 12, dez. 2018, p. 321-330. Disponível em: https://seer.ufrgs.br/renote/article/view/89250/51491. Acesso em: 02 abr. 2019.

MALLMANN, E. M.; SCHNEIDER, D.; MAZZARDO, M. D. Fluência TecnológicoPedagógica (FTP) dos Tutores. RENOTE, v. 11, n. 3, dez. 2013, p. 01-10. Disponível em: <https://bit.ly/2W2sdMp>. Acesso em: 12 set. 2017.

MARCONI, M. A; LAKATOS, E. M. Fundamentos de metodologia científica. 5. ed. São Paulo: Atlas, 2003.

MAZZARDO, M. D. Recursos educacionais abertos: inovação na produção de materiais didáticos dos professores do ensino médio. 2018. Tese (doutorado em Educação, especialidade de Educação a Distância e eLearning (EDeL) - Universidade Aberta de Portugal, Portugal, 2018. Disponível em: https://bit.ly/2WhkiLg. Acesso em: 08 de fev. 2019.

MCAULEY, A.; STEWART, B;, SIEMENS, G.; E CORMIER, D. Massive open online courses digital ways of knowing and learning. The MOOC Model for Digital Practice. Charlottetown, Canada: University of Prince Edward Island. 2010. Disponível em: http://davecormier.com/edblog/wp-content/uploads/MOOC_Final.pdf. Acesso em: 10 abr. 2019.

OLIVEIRA, M. M. de. Como fazer pesquisa qualitativa. 7. ed. Revisada e atualizada. Petrópolis, RJ: Vozes, 2016.

PELZEL, M. Digital Fluency vs Digital Literacy. 2019. Disponível em https://edtechfactotum.com/digital-fluency-vs-digital-literacy/. Acesso em: 01 out. 2019.

SHAPIRO, S.S.; WILK, M. An analysis of variance test for normality (complete samples). Biometrika, 52, 1965. p. 591-611.

SHIMABUKURO, J. SPOCs Are MOOC Game Changers. In: Educational Technology and Change Journal. 2013. Disponível em: https://etcjournal.com/2013/09/26/spocs-are-mooc-game-changers/. Acesso em: 10 nov. 2017.

UNESCO. Um guia básico sobre recursos educacionais abertos (REA). 2011. Disponível em: https://goo.gl/N1Fouu. Acesso em: 20 mar. 2017.

UNESCO. Diretrizes para Recursos Educacionais Abertos (REA) no Ensino Superior. 2015. Disponível em: https://goo.gl/7ztRmZ. Acesso em: 20 mar. 2017.

WILEY, D. A. Open Education License Draft. 2007. Disponível em: https://goo.gl/t2gZCQ. Acesso em: 03 de jul. 2018.

WILEY, D. A. The Access Compromise And The 5th R. 2014. Disponível em: https://goo.gl/DLH5J3. Acesso em: 05 de jul. 2018. 